\title{
Individual and household risk factors of severe acute malnutrition among under- five children in Mao, Chad: a matched case- control study
}

Jovana Dodos ${ }^{1 *}$ D, Chiara Altare ${ }^{1}$, Mahamat Bechir ${ }^{2}$, Mark Myatt $^{3}$, Brigitte Pedro ${ }^{4}$, Francois Bellet ${ }^{5}$, Jean Lapegue ${ }^{1}$, Joachim Peeters ${ }^{1}$ and Mathias Altmann ${ }^{1}$

\begin{abstract}
Background: Severe acute malnutrition (SAM) is one of the leading causes of morbidity and mortality in Chad. The reasons behind persistently high prevalence of SAM in the Kanem region are still poorly understood, leaving national and international partners without clearly identified drivers to address. Current knowledge of SAM determinants in this context is largely based on very limited data. The aim of this study was thus to investigate individual and householdlevel risk factors for SAM among under-five children in Mao health district.

Methods: A matched case-control study was conducted on 411 (137 cases and 274 controls) children aged 6-59 months with their caretakers from mid-February to August 2017. Data were collected by using a structured interviewer administered questionnaire, anthropometric measurements and through direct observations of household environment. Controls were matched to their cases on place of residence and on age ( \pm 3 months). Data were double-entered, processed and analysed using Epi Info 7.2.0.1. Conditional logistic regression was used to analyse the association of independent variables with SAM. For multivariable analysis, two models were constructed to investigate risk factors for SAM, at individual and household level. A stepwise backwards elimination approach with a significance level of $p=0.05$ was used to build the final models.

Results: At the individual level, SAM was significantly associated with diarrhoea [AOR $(95 \% \mathrm{Cl})=10.7(4.2-27.3)]$, fever $[\mathrm{AOR}(95 \% \mathrm{Cl})=8.4(3.1-22.8)]$, vomiting $[\mathrm{AOR}(95 \% \mathrm{Cl})=7.6(3.0-19.7)]$, being stunted $[\mathrm{AOR}(95 \% \mathrm{Cl})=5.3$ $(1.7-16.3)]$, and type of complementary meal [AOR $(95 \% \mathrm{Cl})=4.4(1.0-19.6)]$. At the household level, SAM was significantly associated with undernourished caretaker [AOR $(95 \% \mathrm{Cl})=2.6(1.2-5.5)]$, caretaker's hand washing habits [AOR $(95 \% \mathrm{Cl})=1.9(1.2-3.1)]$, absence of toilet $[\mathrm{AOR}(95 \% \mathrm{Cl})=1.9(1.1-3.6)]$, caretaker's marriage status $[\mathrm{AOR}(95 \% \mathrm{Cl})=7.7(2.0-30.1)]$, and low household food diversity [AOR $(95 \% \mathrm{Cl})=1.8(1.0-3.1)]$.

Conclusion: The present study identified the need to address both treatment and prevention of infections in children through an integrated approach. Well-organized efforts to improve child feeding practices, household hygiene and sanitation conditions, women's nutritional status, along with increasing household food diversity are likely to lead to improved nutritional status of children in this setting.
\end{abstract}

Keywords: Severe acute malnutrition, Childhood illnesses, Household determinants, Risk factors

\footnotetext{
* Correspondence: wash1@actioncontrelafaim.org

${ }^{1}$ Action Contre la Faim, 14/16 Boulevard Douaumont - CS 80060, 75854

PARIS, CEDEX 17, France

Full list of author information is available at the end of the article
} 


\section{Background}

Severe acute malnutrition (SAM) is the most extreme form of acute undernutrition, resulting from acute food shortages, a recent bout of illness, inappropriate child care or feeding practices, or a combination of these factors. SAM is defined by a low mid-upper-arm-circumference (MUAC), and/or a weight-for-height below - 3 Z-scores of the median WHO growth standards [1] and/or presence of bilateral pitting oedema [2].

Severely malnourished children have weakened immunity, are susceptible to long term developmental delays, and have 5-20 times higher risk of death compared to well-nourished children [3]. SAM can be a direct cause of child death, or it can act as an indirect cause by dramatically increasing the case fatality rate in children suffering from common childhood illnesses such as diarrhoea, pneumonia or measles. Children experiencing SAM can face long-term consequences for their future health, learning and economic performance [4].

In 2016, nearly 52 million children under-five suffered from acute malnutrition and 17 million from severe acute malnutrition [5]. Southern Asia and Sub-Saharan Africa bear the greatest share of SAM children; around $75 \%$ of all severely malnourished children live in lower-middle income countries [5], including Chad, where the prevalence of SAM is persistently high.

Chad, after Somalia, has the second highest under-five mortality rate in the world (139 deaths per 1000 live births in 2015) [6, 7]. In order to address the critical nutrition situation in the country, the Ministry of Health of the Republic of Chad has been implementing programmes to strengthen nutritional surveillance and overall management of acute malnutrition. Despite all the efforts made by the Government and its technical and financial partners, the results of 2017 nutrition survey are concerning: prevalence of SAM was estimated at 3.9\% and of Global Acute Malnutrition (GAM) at $13.9 \%$. Nutritional situation in the country deteriorated compared to 2016, when the prevalence of SAM and GAM at the national level was 2.6 and $11.9 \%$, respectively. The Sahelian zone of the country has been especially affected. GAM prevalence among children under five in the Kanem region was estimated at 19.2\% [15.4-23.7], well beyond the commonly used threshold for a public health emergency [8].

Action Contre la Faim (ACF), an international non-governmental organization, has been working in Kanem since 1980s. According to a contextual nutrition causal analysis conducted in Kanem in 2012 [9], major drivers of undernutrition include high prevalence of childhood illnesses, poor access to healthcare, climatic shocks, insufficient agricultural production, poor access to safe drinking water, inadequate hygiene practices, insufficient access to markets and high maternal workload.
Building upon this evidence, we strived to identify and quantify individual and household-level risk factors leading to SAM among under-five children in order to achieve greater understanding of SAM determinants and assess the strength of association. This would allow more effective design and prioritisation of interventions, in addition to better targeting of the most vulnerable populations.

\section{Methods}

\section{Study setting and design}

ACF and its partner in Chad Alliance Sahélienne de Recherches Appliquées pour le Développement Durable (ASRADD), conducted a matched case-control study in Mao city, the capital of Kanem region, Chad. Set in a desert area, Mao city is located in a remote zone, difficult to reach. It has an estimated population of 19,000 inhabitants [10]. The catchment area of Mao health centre covers 54 villages within a $10 \mathrm{~km}$ radius.

\section{Selection of cases}

Cases were defined as SAM children, between six and 59 months of age, newly admitted, relapsed or readmitted to the nutritional Outpatient Therapeutic Program (OTP) of Mao health centre. Anthropometric criteria for admission to the OTP were as follows: MUAC < $115 \mathrm{~mm}$ and/or weight for height Z-score (WHZ) $<-3$ standard deviations (SD) and/or presence of bilateral oedema. Children who did not reside in the 54 villages under the jurisdiction of Mao health centre and those who we were not able to follow up during household visits (due to incorrect data provided by caretakers at the time of initial interview in the health centre) were not eligible for inclusion in the study.

\section{Selection of controls}

Controls were children aged six to 59 months, not undernourished (defined as MUAC $\geq 125 \mathrm{~mm}$ and weight for height Z-score (WHZ) of $\geq-1.5 \mathrm{SD}$ on the day of the survey and without signs of bilateral oedema), in good general health and without known past episodes of SAM.

In order to study specifically individual and household-level risk factors, controls were matched to their cases on their place of residence (village / neighbourhood). We also matched cases and controls on age ( \pm 3 months), as it is a potential cofounder of the association.

\section{Sample size calculation}

Sample size was calculated using standard formula for a matched case-control study [11]. As several risk factors were considered, a proportion of $80 \%$ among controls, e.g. proportion of households without tap water [12], 
was selected in order to yield the maximum sample size. We used power $(1-\beta)$ of $80 \%$ and significance $(\alpha)$ of $5 \%$; control to case ratio of $2: 1$ to detect an odds ratio of 3 (considered as a moderately strong risk factor). With the given parameters, the sample size required for the study was 360 , collected as 120 cases and 240 controls. Resources allowed to increase the sample size to 411, including 137 cases and 274 controls. Such an increment in sample size augmented the power of the study.

\section{Data collection instruments and procedure}

Data collection lasted from the beginning of February to mid-August 2017.

Cases were recruited during the admission days to the OTP in Mao health centre. Anthropometric measures were extracted from the OTP register. Data on health and nutritional status of caretaker, household WASH (water, sanitation and hygiene) conditions, socio-economic and demographic data were collected on the following day during the household visit through face-to-face interview, using a structured interviewer administered questionnaire, and direct observations.

Controls were recruited from the same neighbourhood where cases reside. After completing the interview with the case caretaker, data collectors visited the closest neighbouring households to identify eligible children for the controls. Anthropometric measurements of the controls were conducted at their household by the two team members in charge of this task. Weight $(\mathrm{kg}, \mathrm{g})$ was measured using UNICEF electronic scale (to the nearest of $0.1 \mathrm{~kg}$ ); length and height $(\mathrm{cm})$ were measured by UNICEF portable measuring board (to the nearest $\mathrm{mm}$ ). Presence of oedema was identified if a bilateral depression remained $3 \mathrm{sec}$ after the pressure was released.

The questionnaire was based on the review of available literature, findings from two nutrition causal analyses studies ("Link NCA") conducted in Kanem [9] and Ouaddaï region [13], as well as internal consultations with ACF's program managers in Mao.

The questionnaire was developed in French and translated into local languages (Goran and Kanembou) through a group discussion with data collectors who had a good command of both French and the local languages. Data collectors were recruited locally from a pool of enumerators who had previously worked with ACF and ASRADD. They were trained for 2 days by the principal investigator in filling out the questionnaire and use of measurement devices. Each data collector was accompanied by the principal investigator for at least 3 interviews during the survey pilot, to provide hands-on training. Data collectors were divided in two teams, each with a supervisor who ensured the quality control of the collected data.

\section{Variables included in the study}

For the purpose of this study, we broadly categorized risk factors for SAM into two groups: individual and household-level risk factors for SAM.

\section{Individual risk factors}

Individual risk factors included sex, diet, recent morbidity, stunting and child care and feeding practices. Age of cases was copied from the OTP registers. Age of controls was identified by asking caretakers about the age of a child. To identify retrospective morbidity in children, caretakers were asked about any occurrence of disease during the past 15 days. Diarrhoea was defined as three or more loose or liquid stools per day. Stunting in children was defined as a height-for-age Z-score (HAZ) $<-2$ SD as per 2006 WHO Growth Standards. Immunization status of the children was assessed based on vaccination card, if present. Signs of traditional healing practices were identified by asking caretakers if child experienced recent dental extraction, removal of uvula, scarification and/or burns. Early complementary feeding was defined as introducing foods or liquids other than breast milk before or at 6 months of age.

\section{Household-level risk factors}

Household-level risk factors included variables related to caretaker's nutritional status, caretaker's health seeking behaviour and personal habits, household WASH conditions, household demographic and socio-economic profile. Nutritional status of the caretakers was defined with MUAC; a threshold of $220 \mathrm{~mm}$ [14] was used to define undernutrition. Early pregnancy was defined as a pregnancy in women under the age of 18. Antenatal care follow-up was defined as consulting with health professionals during the last pregnancy. Recent morbidity in the household was defined as presence of symptoms (fever, diarrhoea, vomiting, cough) during the past 15 days in family members other than a child.

Samples of drinking water used for the child included in the study were taken in each household. Physio-chemical and bacteriological qualities were analysed with Wagtech ${ }^{\circ}$ water safety kit. Good water quality was defined according to national standards: Escherichia coli per $100 \mathrm{ml}=0$ and $0.2<$ free residual chlorine $<0.5 \mathrm{mg} / \mathrm{l}$ and NTU (Nephelometric Turbidity Unit) $<5$. The concentration of Escherichia coli per $100 \mathrm{ml}$ was also used as a continuous variable in dose-response analysis. Minimum water quantity was defined according to the SPHERE standards [15] with a threshold set at 151 per person per day. Hand washing knowledge was identified by reporting five key times for hand washing: before preparing food, before 
eating, before breastfeeding or feeding a child, after defecation/using toilet, after managing child's faeces. Hand washing practice was identified by asking caretakers to demonstrate the way they usually wash hands (e.g. using water, using soap, rubbing hands at least three times). A hand washing behaviour score (ranging from 0 to 10) was created by summing up responses related to hand washing knowledge and hand washing practice. The ability to name five key times for hand washing were also used as independent variables with values yes/no. Environmental hygiene (e.g. presence of faecal material in the kitchen/ child's play areas, presence of stagnant water and use of mosquito bed nets) was assessed through direct observation of the household environment.

Household Food Diversity Score (0-12) was assessed over the 7 days preceding the interview and included 12 food groups consumed at the household level. Household food diversity was defined as low if the score was below or equal to six [16]. Preoccupation of caretaker that the household will not have enough food to satisfy basic family needs was used as a proxy for food insecurity. Low income was defined as having monthly financial resources below 35.000 FCFA (Central African Financial Cooperation Franc), which corresponded to the median in our study.

\section{Data quality control, processing and analysis}

Data collectors were paired and supervised during data collection. Before data entry, each questionnaire was checked by the supervisors for completeness and logical consistency. Overall data collection and entry were supervised by the principal investigator. Data were double-entered, processed and analysed using Epi Info 7.2.0.1.

Descriptive statistics were expressed as percentages and frequency. Conditional logistic regression for matched data was used to identify factors independently associated with the outcome. Variables that were significant in bivariate analysis were considered for inclusion in the multivariable conditional logistic regression models. A $p$-value $=0.05$ was considered to be significant.

For studying the risk factors of SAM at the two levels, individual and household, we treated the data as two separate matched case-control studies and constructed two models:

1. First model included risk factors at child/ individual level: sex, diet, recent morbidity, stunting, child care and feeding practices.

2. The second model included risk factors at household level: caretaker's nutritional status, caretaker's health seeking behaviour and personal habits, household WASH conditions, household demographic and socio-economic profile.
A stepwise backwards elimination approach with a significance level of $p=0.05$ was used to build the final models. Multicollinearity was assessed using variance inflation factor (VIF). None of the variables had VIF $>4$.

\section{Results}

A total of 137 cases and 274 controls were included in the study. A selection of descriptive results is presented in Table 1.

\section{Individual risk factors of SAM}

Average age was 15.4 and 15.8 months among cases and controls, respectively. Overall, $56 \%$ of the participants were female. For $83 \%$ of the study participants, vaccination card was not present in the household during the survey. Among those who were immunized $(N=70)$, completed immunization status according to the national program was present in 8 and $6 \%$ of cases and controls, respectively. Less than $20 \%$ of study participants were exclusively breastfed during first 6 month of life. There was no difference between cases and controls with regard to frequency of feeding.

Bivariate analyses showed that sex, recent morbidity in a child, being stunted, non-exclusive breastfeeding during first 6 months of life, type of complementary meal introduced (family dish), age when the first complementary meal was introduced ( $\leq 6$ months), and signs of traditional healing practices on a child were significantly associated with SAM (Table 2). In the multivariable analysis, presence of diarrhoea $[\mathrm{AOR}(95 \% \mathrm{CI})=$ $10.7(4.2-27.3)]$, fever [AOR $(95 \% \mathrm{CI})=8.4(3.1-22.8)]$, vomiting [AOR $(95 \% \mathrm{CI})=7.6(3.0-19.7)]$, being stunted [AOR $(95 \% \mathrm{CI})=5.3(1.7-16.3)]$, and type of complementary meal introduced (family dish) [AOR $(95 \% \mathrm{CI})=4.4$ (1.0-19.6)] remained significantly associated with SAM (Table 2).

\section{Household risk factors for SAM}

Multivariable analysis on the household-level risk factors showed that the odds of SAM was significantly higher among children whose caretakers were undernourished $($ MUAC $<220 \mathrm{~mm})$ [AOR $(95 \% \mathrm{CI})=2.6 \quad(1.2-5.5)$ ], caretakers' habit of less frequent hand washing after defecation/ using toilet [AOR $(95 \% \mathrm{CI})=1.9(1.2-3.1)$ ], absence of toilet in the household [AOR $(95 \% \mathrm{CI})=1.9$ (1.1-3.6)], marriage status of caretakers (not married/ lives alone) $[\mathrm{AOR}(95 \% \mathrm{CI})=7.7(2.0-30.1)]$, and low household food diversity [AOR $(95 \% \mathrm{CI})=1.8(1.0-3.1)$ ] (Table 3). Recent morbidity in the household, early pregnancy, hand washing behaviour score, destination of child's faeces (outside the house), monthly hygiene expenses $<2000$ FCFA, educational status of caretaker (did not attend any school), monthly financial resources $<35.000$ FCFA, and food insecurity showed an 
Table 1 General characteristics of the study participants, Mao health district, February-August 2017

\begin{tabular}{|c|c|c|c|}
\hline Characteristic & Cases $N=137$ & Controls $N=274$ & Total $N=411$ \\
\hline \multicolumn{4}{|l|}{ Demographic and socio-economic profile } \\
\hline Number of people in the household, mean & 5.61 & 5.91 & 5.81 \\
\hline Number of children under five, mean & 1.74 & 1.86 & 1.82 \\
\hline Household possesses livestock & $76(55.47 \%)$ & $172(62.77 \%)$ & $248(60.34 \%)$ \\
\hline Agricultural activities by the household & $32(23.36 \%)$ & $59(21.53 \%)$ & $91(22.14 \%)$ \\
\hline \multicolumn{4}{|l|}{ Child caretakers' profile and health seeking behaviour } \\
\hline Age of caretakers (years), mean & 25.42 & 25.74 & 25.63 \\
\hline Income generating status / Not employed & $125(91.24 \%)$ & $247(90.15 \%)$ & $371(90.51 \%)$ \\
\hline Follow antenatal care visits & $118(86.13 \%)$ & $250(91.24 \%)$ & $368(89.54 \%)$ \\
\hline \multicolumn{4}{|l|}{ Usual practice when child is sick } \\
\hline Taking child to the health centre & $50(36.50 \%)$ & $117(42.70 \%)$ & $167(40.63 \%)$ \\
\hline Self-treatment methods & $85(62.04 \%)$ & $156(56.93 \%)$ & $241(58.64 \%)$ \\
\hline Caretaker participates in decision making on expenses for child health care & $10(7.30 \%)$ & $11(4.01 \%)$ & $21(5.11 \%)$ \\
\hline \multicolumn{4}{|l|}{ Reasons for not going to health centre to consult with health professionals } \\
\hline High prices & $64(46.72 \%)$ & $120(43.80 \%)$ & $184(44.77 \%)$ \\
\hline Lack of time & $21(15.33 \%)$ & $43(15.69 \%)$ & $64(15.57 \%)$ \\
\hline Lack of means of transport & $9(6.57 \%)$ & $28(10.22 \%)$ & $37(9.00 \%)$ \\
\hline Long distances & $7(5.11 \%)$ & $13(4.74 \%)$ & $20(4.87 \%)$ \\
\hline \multicolumn{4}{|l|}{ Household WASH conditions } \\
\hline Soap is present in the household & $128(93.43 \%)$ & $259(94.53 \%)$ & $387(94.16 \%)$ \\
\hline Where toilet is not present, family practice open defecation & $71(51.82 \%)$ & $120(43.79 \%)$ & $191(46.47 \%)$ \\
\hline \multicolumn{4}{|l|}{ Principal water source for the household } \\
\hline Tap & $57(41.61 \%)$ & $118(43.07 \%)$ & $175(42.58 \%)$ \\
\hline Forage with a hand pump & $47(34.31 \%)$ & $89(32.48 \%)$ & $136(33.09 \%)$ \\
\hline Open well & $26(18.98 \%)$ & $42(15.33 \%)$ & $68(16.15 \%)$ \\
\hline Other & $7(5.11 \%)$ & $25(9.12 \%)$ & $32(7.79 \%)$ \\
\hline Time needed to collect water $\geq 30 \mathrm{~min}$ & $71(51.82 \%)$ & $184(67.15 \%)$ & $255(62.04 \%)$ \\
\hline \multicolumn{4}{|l|}{ Persons in charge of water collection } \\
\hline Women & $132(96.35 \%)$ & $265(96.72 \%)$ & $397(96.59 \%)$ \\
\hline Men & $15(10.95 \%)$ & $28(10.22 \%)$ & $43(10.46 \%)$ \\
\hline Children & $75(54.74 \%)$ & $134(48.91 \%)$ & $209(50.85 \%)$ \\
\hline Household has less than 15 I per person per day & $10(7.30 \%)$ & $14(5.11 \%)$ & $24(5.84 \%)$ \\
\hline Container used for water transport is dirty & $70(51.09 \%)$ & 107 (39.05\%) & $177(43.07 \%)$ \\
\hline Water is stored in an unhygienic place & $115(83.94 \%)$ & $200(72.99 \%)$ & $315(76.64 \%)$ \\
\hline Water is treated before consumption & $5(3.65 \%)$ & $10(3.65 \%)$ & $15(3.65 \%)$ \\
\hline Good drinking water quality at point-of-use & $0(0.0 \%)$ & $0(0.0 \%)$ & $0(0.0 \%)$ \\
\hline Escherichia coli $=0$ & $28(20.44 \%)$ & $44(16.06 \%)$ & $72(17.52 \%)$ \\
\hline Presence of faecal material (human or animal) around the household & $99(72.26 \%)$ & $200(72.99 \%)$ & $299(72.57 \%)$ \\
\hline Presence of faecal material (human or animal) in the child's play areas & $65(47.45 \%)$ & $124(45.26 \%)$ & $189(45.99 \%)$ \\
\hline Kitchen utensils or food leftovers are left uncovered on the floor & $55(40.15 \%)$ & $96(35.04 \%)$ & $151(36.74 \%)$ \\
\hline Household uses mosquito bed nets & $21(15.33 \%)$ & $35(12.77 \%)$ & $56(13.63 \%)$ \\
\hline
\end{tabular}

Cases = children 6-59 months, MUAC $<115 \mathrm{~mm}$ and/or weight for height Z-score $(W H Z)<-3 S D$ and/or presence of bilateral oedema

Controls = children 6-59 months, MUAC $\geq 125 \mathrm{~mm}$ and weight for height Z-score (WHZ) of $\geq-1.5 \mathrm{SD}$, without sign of bilateral oedema 
Table 2 Individual risk factors of SAM, Mao health district, February-August 2017

\begin{tabular}{|c|c|c|c|c|c|}
\hline Child characteristic & Cases (\%) & Controls (\%) & COR $(95 \% \mathrm{Cl})$ & AOR $(95 \% \mathrm{Cl})$ & $P$-value \\
\hline Sex, female & $80(58.4)$ & $150(54.7)$ & $4.9(1.0-24.0)$ & & \\
\hline Diarrhoea in the last 15 days & $124(90.5)$ & $86(31.4)$ & $18.9(19.2-39.1)$ & $10.7(4.2-27.3)$ & 0.000 \\
\hline Fever in the last 15 days & $123(89.8)$ & $104(38.0)$ & $18.3(8.5-39.8)$ & $8.4(3.1-22.8)$ & 0.000 \\
\hline Cough in the last 15 days & $87(56.9)$ & $67(24.5)$ & $4.1(2.6-6.5)$ & & \\
\hline Vomiting in the last 15 days & $75(54.7)$ & $27(9.0)$ & $12.6(6.5-24.6)$ & $7.6(3.0-19.7)$ & 0.000 \\
\hline Being stunted & $123(89.8)$ & $175(63.9)$ & $6.77(3.3-13.8)$ & $5.3(1.7-16.3)$ & 0.004 \\
\hline Non-exclusive breastfeeding & $120(87.6)$ & $221(80.7)$ & $1.9(1.0-3.6)$ & & \\
\hline Complementary feeding at $\leq 6$ months & $91(66.4)$ & $155(56.6)$ & $1.6(1.0-2.5)$ & & \\
\hline Type of first complementary meal, family dish & $13(9.5)$ & $14(5.1)$ & 2. $1(0.9-4.9)$ & $4.4(1.0-19.6)$ & 0.050 \\
\hline Signs of traditional curing practices on a child & $60(43.8)$ & $83(30.3)$ & $2.0(1.3-3.2)$ & & \\
\hline
\end{tabular}

SAM severe acute malnutrition, $C O R$ crude odds ratio, $C l$ confidence interval, $S D$ standard deviation, $A O R$ adjusted odds ratio, Statistically significant difference at minimum level of $p=0.05$

association with SAM in bivariate analysis, but were not significantly associated in the multivariable analysis.

\section{Discussion}

Our study investigated individual and household risk factors for SAM among children aged 6-59 months in Mao health district, Kanem region, Chad. Using a matched case-control design, we identified and quantified the effect of several risk factors at both levels. The results point to the need for a package of interventions to address infections at the child level through appropriate treatment and by intervening on hygiene and socio-economic status of the household.

We found a strong association between recent morbidity in a child and SAM. This result supports the evidence on the well-accepted link between infections and nutritional status of children, as they affect dietary intake, uptake and utilization. Interactions between infections and undernutrition have long been described as a vicious circle, one being a risk factor for the other, and vice versa [17-19]. These results are in line with the findings from another study conducted in south-eastern Chad [20] which showed that recent episodes of diarrhoea, fever and pneumonia were strongly associated with SAM. This finding points to the importance of treating infections in a prompt manner (for example with Oral Rehydration Salt in case of diarrhoea and vomiting), and preventing infections in children through an integrated approach to tackle environmental health, household socio-economic status and caretaker's habits.

Absence of toilet in the household and caretakers' hand washing habits were significantly associated with both SAM and diarrhoea. This is consistent with the existing evidence [21-23]. Poor access to sanitation and

Table 3 Household risk factors for SAM, Mao health district, February-August 2017

\begin{tabular}{|c|c|c|c|c|c|}
\hline Characteristic & Cases (\%) & Controls (\%) & COR $(95 \% \mathrm{Cl})$ & AOR $(95 \% \mathrm{Cl})$ & $P$-value \\
\hline Recent morbidity in the household & $42(30.7)$ & $59(21.5)$ & $1.66(1.0-2.7)$ & & \\
\hline MUAC of mother/caretaker $<220 \mathrm{~mm}$ & 19 (13.9) & $14(5.1)$ & $3.0(1.4-6.1)$ & $2.6(1.2-5.5)$ & 0.015 \\
\hline Early pregnancy $\leq 18$ years & $29(21.2)$ & $33(12.0)$ & $1.9(1.1-3.2)$ & & \\
\hline Hand washing behaviour score, mean (SD) & $6.8(1.0)$ & $7.0(0.9)$ & $0.8(0.6-1.0)$ & & \\
\hline Not washing hands after defecation/using toilet & $74(54.0)$ & $110(40.2)$ & $1.8(1.2-2.8)$ & $1.9(1.2-3.1)$ & 0.009 \\
\hline Absence of toilet in the household & $78(56.9)$ & $129(47.1)$ & $2.3(1.2-4.1)$ & $1.9(1.1-3.6)$ & 0.046 \\
\hline Destination of child's faeces, outside the house & $117(85.4)$ & $216(78.8)$ & $1.9(1.0-3.8)$ & & \\
\hline Monthly hygiene expenses < 2000 FCFA & $66(48.2)$ & $99(36.1)$ & $2.0(1.2-3.4)$ & & \\
\hline Marriage status of caretaker /lives alone & $9(6.6)$ & $3(1.1)$ & $6.0(1.6-22.1)$ & $7.7(2.0-30.1)$ & 0.003 \\
\hline Caretaker did not attend any school & $18(13.1)$ & $18(6.6)$ & $2.9(1.2-6.6)$ & & \\
\hline Monthly financial resources $<35.000$ FCFA & $75(54.7)$ & $123(44.9)$ & $1.5(0.9-2.3)$ & & \\
\hline Food insecurity & $46(33.6)$ & $63(23.0)$ & $1.9(1.1-3.1)$ & & \\
\hline Household Food Diversity Score $\leq 6$ & $64(46.7)$ & $100(36.5)$ & $1.9(1.1-3.2)$ & $1.8(1.0-3.1)$ & 0.041 \\
\hline
\end{tabular}

SAM severe acute malnutrition, $C O R$ crude odds ratio, $C l$ confidence interval, $S D$ standard deviation, AOR adjusted odds ratio, Statistically significant difference at minimum level of $p=0.05 ;$ MUAC mid upper arm circumference, FCFA central african franc, 1 XAF $=0,00152 \mathrm{EUR}$ 
failure to wash hands after defecation increase the risk of faecal contamination of home surroundings, which leads to ingestion of faecal pathogens causing infections such as diarrhoea. This ultimately results in increased risk of undernutrition and SAM. Findings from a recent study conducted in Bangladesh are in concordance with these results [24]. Actions aiming at improving WASH conditions and hygiene practices at the household level are therefore a priority.

Similarly, contaminated water increases the risk of direct ingestion of faecal material [25]. To our surprise, we did not observe a significant association between point-of-use water quality and SAM. None of the households included in the study had a good drinking water quality. Probably, cases and controls had access to the same water source, as one of the recruitment criteria was proximity. This universal exposure could have hidden a real risk. Dose-response analysis of increasing levels of contamination also did not show any association. Our findings may indicate that in this context pathogens are rather transmitted through poor sanitation and hand hygiene than through poor quality of drinking water, as reported in Nigeria [26].

The results from this study indicated that the type of complementary meal introduced (family dish) was significantly associated with SAM. "Family dish", a cereal based porridge with okra and meat sauce, was probably inadequate in terms of energy, protein and micronutrients, or nutrient density in relation to the child's needs [27]. In the Kanem region, family dish is usually served in large plates, from which all family members eat together by hands while sitting on mats or carpets. Such practice could also represent a transmission pathway of enteric infections through unhygienic feeding practices and poor hand hygiene of caretakers and other family members $[28,29]$.

In our study, the odds of SAM were significantly higher among children who were stunted. While the causal relation between stunting and wasting is little explored and stunting cannot be clearly identified as a direct risk factor for SAM [30], experiencing chronic nutritional deficits greatly increases susceptibility to and severity of infections, which are proximate determinants of SAM.

Results of the present study also showed that maternal undernutrition increases the risk of having a malnourished child, which is consistent with other research findings [31, 32]. Poor maternal nutrition has a detrimental impact on nutritional status of a child at the foetal stage and beyond. One negative consequence is in-uterus growth retardation, which results in infants being born small for gestational age. Evidence shows a negative association between small for gestational age and future child nutritional status [33, 34]. Unfortunately, data on children's weight at birth were not available, so we could not explore this association. However, in our context, poor nutritional status of both mother/caretaker and child are likely to be related to the low socio-economic status of the household [35]: risk of SAM was higher for children in households with one bread-winner and with the low household food diversity score. These observations are in line with previous findings [36], which showed that lower food diversity score was associated with significantly higher likelihood of wasting. However, this association was found significant in rural areas but not in urban and further research is needed to confirm and clarify relationship between various food diversity indicators and SAM.

With regard to the caregiver's marital status and its association with SAM, the very broad confidence interval reflects the paucity of cases we encountered. This result should therefore be considered with caution. While the link between women's social position and child nutrition is well recognised [37-39], future studies investigating position of women, autonomy and capabilities in the household and in the community could better shed lights on power relations and the mechanisms linking marital status and child undernutrition in this context.

While this is the first study on the individual and household-level risk factors for SAM in the Kanem region, it has some limitations. The study relied on participants' self-reported data, which is prone to recall bias and tendency of respondents to report socially desirable behaviours. However, as this applies to both groups, the possible bias should not affect the strength of associations. Due attention was given to respecting study procedures, including training of data collectors, taking anthropometric measurements and supervision throughout data collection period to minimize this expected bias. Overmatching might have occurred and hindered the identification of risk factors associated with the matching criteria (proximity). Matching on neighbourhood matches on a large number of "implicit" factors (e.g. altitude, climate, food-economy, ethnicity, socio-economic status, extended family, religion, etc.). This means that the association between SAM and these factors could not be, and was not, explored. It may also mean that risk factors that may also associated with location (e.g. water source) may not be identified. Matching on age and sex, however, expands the "search radius" required to find controls. Having more than one matched control per case has the same effect. These procedures help to reduce problems of overmatching when neighbourhood controls are used.

In this study design, the ascertainment of exposure is done after the outcome. This means results lack the element of temporality and therefore causality cannot be implied. Recruiting cases at the health centre may have 
introduced a self-selection bias, as cases who sought care at the health centre may be different than cases who did not. SAM symptoms may have alerted caretaker to go to the health centre, overestimating the odds ratio between recent morbidity and SAM. Nevertheless, this was considered a suitable approach to investigate a rare condition such as SAM. In fact, recruiting cases in the community would have been a long and costly process, and recruiting controls in the health centre was not appropriate to our objective of matching on the place of residence (village/ neighbourhood).

Finally, the data is context specific and special consideration must be taken on extrapolating the findings to other contexts.

\section{Conclusions}

The present study identified the need for an integrated approach to address infections at the child level through appropriate treatment and by intervening on hygiene and socio-economic status of the household. It showed that child morbidity, stunting, type of first complementary meal introduced, marriage and nutritional status of caretaker, hygiene practices and absence of toilet in the context without access to safe drinking water, and low household food diversity are the risk factors for SAM in Mao health district, Kanem region, Chad.

Based on these findings, actions should be designed to prevent and treat childhood illnesses, improve child care and feeding practices, ameliorate sanitation conditions in the households and hygiene practices of caretakers, including hygienic food preparation. Programs focusing on improving women's nutritional status, along with increasing household food diversity are also likely to lead to improved nutritional status of children in this setting.

\footnotetext{
Abbreviations

AOR: Adjusted odds ratio; ASRADD: Alliance Sahelienne de recherches appliquées pour le developpement durable; Cl: Confidence interval; COR: Crude odds ratio; FCFA: Central african financial cooperation franc; GAM: Global Acute malnutrition; HAZ: height-for-age Z-score; INGO: International non-governmental organization; MUAC: Mid upper arm circumference; NTU: Nephelometric turbidity unit; OR: Odds ratio; OTP: Outpatient therapeutic program; SAM: Severe acute malnutrition; SD: Standard deviation; SHPERE: Minimum standards for the delivery of quality humanitarian response; UNICEF: United nations children's fund; VIF: Variance inflation factors; WASH: Water, sanitation and hygiene; WHO: World health organization; WHZ: Weight for Height Z-score
}

\section{Acknowledgements \\ The authors would like to express their sincere gratitude health staff of Mao health centre, project manager, supervisors, data collectors and all other individuals who helped us to carry out this study successfully. We would also like to thank to the caretakers of children who participated in this study for taking their time to provide us with information.}

\section{Disclaimer for UNICEF authors}

The opinions and statements in this article are those of the authors and may not reflect official UNICEF policies.

\section{Funding}

The study was funded by UNICEF country office in Chad.

\section{Availability of data and materials}

The datasets analysed during the current study are in French and are available from the corresponding author on reasonable request.

\section{Authors' contributions}

The authors responsibilities were as follows: Jovana Dodos is a principle investigator, participated in the design of the study, monitored data collection, performed statistical analysis and served as the lead author of the manuscript. Mathias Altmann designed and supervised the study, performed statistical analysis. Mahmat Bechir made a substantial contribution to the local implementation of the study. Chiara Altare \& Mark Myatt assisted in the analysis and interpretation of the data. Francois Bellet, Brigitte Pedro, Jean Lapegue and Joachim Peteers participated in revising this final manuscript. All authors read and approved the final manuscript.

Ethics approval and consent to participate

Legal authorization was obtained from the Ministry of Health, Republic of Chad. Oral informed consents were obtained from the caretakers of eligible children before the interview. Confidentiality of the information given by the respondents was maintained and data were anonymized. All children found malnourished during control-finding in villages were referred to the health centre.

\section{Consent for publication \\ Not applicable. \\ The manuscript does not contain any individual person's data in any form and study participants are not identifiable from the material provided.}

\section{Competing interests}

The authors declare that they have no competing interests.

\section{Publisher's Note}

Springer Nature remains neutral with regard to jurisdictional claims in published maps and institutional affiliations.

\section{Author details}

Action Contre la Faim, 14/16 Boulevard Douaumont - CS 80060, 75854 PARIS, CEDEX 17, France. ${ }^{2}$ Alliance Sahélienne de Recherches Appliquées pour le Développement Durable ASRADD, N'djamena, Chad. ${ }^{3}$ Brixton Health, Powys, UK. ${ }^{4}$ UNICEF Chad, N'djamena, Chad. ${ }^{5}$ UNICEF Regional Office for West and Central Africa, Dakar, Senegal.

Received: 3 January 2018 Accepted: 8 June 2018

Published online: 01 August 2018

References

1. WHO/ UNICEF, Child growth standards and the identification of severe acute malnutrition in infants and children - A Joint Statement, 2009, http:// www.who.int/nutrition/publications/severemalnutrition/9789241598163/en/, Assessed 7 Mar 2018.

2. UNICEF, What is severe acute malnutrition? 2015; https://www.unicef.org/ nutrition/index_sam.html, Assessed 7 Novr 2017.

3. WHO; UNICEF; WFP; UN System Standing Committee on Nutrition, 2007; Community-based management of severe acute malnutrition - A joint statement; http://www.who.int/maternal_child_adolescent/documents/ a91065/en/, Accessed 17 December 2017.

4. World Health Organization. Management of severe malnutrition: a manual for physicians and other senior health workers. Geneva: World Health Organization; 1999.

5. UNICEF/WHO/ World Bank group, Levels and trends on child malnutrition Joint Child Malnutrition Estimates, 2017, https://data.unicef.org/wp-content/ uploads/2017/06/JME-2017_brochure_June-25.pdf, Assessed 12 Mar 2018.

6. Institute for Health Metrics and Evaluation, Health data for Chad, 2016; http://www.healthdata.org/chad, Accessed 1 Nov 2017.

7. UNICEF Chad, Country Programme report 2012-2016; https://www.unicef. org/chad/overview_7120.html, Accessed 15 October 2017.

8. Ministry of Health of the Republic of Chad, UNICEF Chad, SMART National nutrition survey among children under five, 2017; https://reliefweb.int/ 
report/chad/note-de-pr-sentation-synth-tique-des-r-sultats-anthropom triques-et-de-mortalit-r, Accessed 1 Dec 2017.

9. Action Against Hunger, SIDA. Qualitative analysis of malnutrition causes. Kanem region, Chad; 2012. http://linknca.org/etude/region_du_kanem.htm, Accessed 25 Nov 2017

10. Wight J. SQUEAC Districts de Mao et Mondo. Kanem: Coverage Monitoring Network; 2013.

11. Rosner B. Fundamentals of biostatistics. 7th ed. Boston: Cengage Learning; 2010. Print

12. Par Fadil Youssouf M, Madjiade T. Report on initial KAP Survey: water, sanitation and hygiene in Mao: Action Contre la Faim, ASRADD; 2016. http://www.asradd.org/wp-content/uploads/2016/09/Enqu\%C3\%AAte_CAP. pdf, Assessed 1 Dec 2017

13. Action Against Hunger, International Medical Corps, USAID. Causal analysis of undernutrition. Ouaddadai region, Chad: Abdi health district; 2016. http:// linknca.org/etude/district_sanitare_d_abdi_region_du_ouaddai.htm, Accessed 11 Nov 2017

14. Food and Nutrition Technical Assistance III Project (FANTA). Nutrition Assessment, Counseling, and Support (NACS): A User's Guide-Module 2: Nutrition Assessment and Classification, Version 2. Washington, DC: FHI 360/ FANTA; 2016.

15. The SHPERE Project, Humanitarian Chapter and Minimum Standards in Humanitarian Response, 2015; http://www.sphereproject.org/, Accessed 15 Nov 2017.

16. FAO Guidelines for measuring household and individual dietary diversity; 2011; http://www.fao.org/fileadmin/user_upload/wa_workshop/docs/FAOguidelines-dietary-diversity2011.pdf, Accessed 28 Oct 2017.

17. Dewey KG, Mayers DR. Early child growth: how do nutrition and infection interact? Matern Child Nutr. 2011;7(Suppl 3):129-42. https://doi.org/10.1111/ j.1740-8709.2011.00357.x.

18. Bairagi R, Chowdhury MK, Kim YJ, Curlin GT, Gray RH. The association between malnutrition and diarrhoea in rural Bangladesh. Int J Epidemiol. 1987; 16:477-81.

19. Lima AAM, Oriá RB, et al. Geography, Population, Demography, Socioeconomic, Anthropometry, and Environmental Status in the MAL-ED Cohort and Case-Control Study Sites in Fortaleza, Ceará, Brazil. Clin Infect Dis. 2014;59(suppl_4):S287-94. https://doi.org/10.1093/cid/ciu438, Assessed 31 Nov 2017

20. Tesfai C, Ratnayake R, Myatt M. Measuring local determinants of acute malnutrition in Chad: a case-control study. Lancet. 2013;381:S144. https:// doi.org/10.1016/S0140-6736(13)61398-7.

21. Ayana AB, Hailemariam TW, Melke AS. Determinants of acute malnutrition among children aged 6-59 months in public hospitals, Oromia region, West Ethiopia: a case-control study. BMC Nutr. 2015;1:34. https://doi.org/10.1186/ s40795-015-0031-9.

22. Ambadekar N, Zodpey SP. Risk factors for severe acute malnutrition in under-five children: a case-control study I rural part of India. science Direct. 2017; https://doi.org/10.1016/j.puhe.2016.07.018, Assessed 1 Dec 2017

23. Wubante AA. Determinants of infant nutritional status in Dabat district, North Gondar, Ethiopia: a case control study. PLoS One. 2017;12(3): e0174624. https://doi.org/10.1371/journal.pone.0174624

24. Raihan MJ, Farzana FD, Sultana S, Haque MA, Rahman AS, Waid JL, et al. Examining the relationship between socio-economic status, WASH practices and wasting. PLoS One. 2017;12(3):e0172134. https://doi.org/10.1371/journal. pone. 0172134

25. Dangour AD, Watson L, Cumming O, Boisson S, Che $Y$, et al. Interventions to improve water quality and supply, sanitation and hygiene practices, and their effects on the nutritional status of children. Cochrane Database Syst Rev. 2013;(8):CD009382. https://doi.org/10.1002/14651858.CD009382.pub2.

26. Oloruntoba EO, Folarin TB, Ayede Al. Hygiene and sanitation risk factors of diarrhoeal disease among under-five children in Ibadan, Nigeria. Afr Health Sci. 2014; https://doi.org/10.4314/ahs.v14i4.32, Assessed 15 Mar 2018

27. Abeshu MA, Lelisa A, Geleta B. Complementary feeding: review of recommendations, feeding practices, and adequacy of homemade complementary food preparations in developing countries - lessons from Ethiopia. Front Nutr. 2016;3:41. https://doi.org/10.3389/fnut.2016.00041.

28. Guatam OP, Esteves Mills J, Chitty A, Curtis V. Policy Brief: Complementary Food Hygiene: An overlooked opportunity in the WASH. Nutr Health sectors. 2015, 2015; LSHTM and SHARE

29. Agustina R, Sari TP, Satroamidjojo S, et al. Association of food-hygiene practices and diarrhoea prevalence among Indonesian young children from low socioeconomic urban areas. BMC Public Health. 2013; http://www.ncbi. nlm.nih.gov/pmc/articles/PMC3813984, Assessed 20 Mar 2018

30. Khara T, Dolan C, The relationship between wasting and stunting, policy, programming and research implications (Technical Briefing Paper), Emergency Nutrition Network, USAID, 2014.

31. Fuchs C, Sultana T, Ahmed T, Iqbal Hossain M. Factors associated with acute malnutrition among children admitted to a Diarrhoea treatment Facility in Bangladesh. International Journal of Pediatrics. 2014;2014:267806. https:// doi.org/10.1155/2014/267806.

32. Purandare CN. Maternal nutritional deficiencies and interventions. Journal of Obstetrics and Gynaecology of India. 2012;62(6):621-3. https://doi.org/10. 1007/s13224-013-0347-9.

33. Hien NN, Kam S. Nutritional status and the characteristics related to malnutrition in children under five years of age in Nghean, Vietnam, 2008. Med Public Health. https://doi.org/10.3961/jpmph.2008.41.4.232.

34. Fernandez ID. John H. Himes, Mercedes de Onis, Prevalence of nutritional wasting in populations: building explanatory models using secondary data. Bull World Health Organ. 2002;80(4):282-91.

35. Pravana NK, Piryani S, Chaurasiya SP, Kawan R, Thapa RK, Shrestha S. Determinants of severe acute malnutrition among children under 5 years of age in Nepal: a community-based case-control study. BMJ Open. 2017; https://doi.org/10.1136/bmjopen-2017-017084.

36. Amugsil DA, Mittelmark MB, Lartey A. Dietary diversity is a predictor of acute malnutrition in rural but not in urban settings: evidence from Ghana. British Journal of Medicine \& Medical Research. 2014;4(25):4310-24.

37. Van den Bold M, Quisumbing AR, Gillespie S. Women's Empowerment and Nutrition: An Evidence Review. SSRN Electron J. 2013; https://doi.org/10. 2139/ssrn.2343160

38. Na M, Jennings $L$, Talegawkar SA, Ahmed S. Association between women's empowerment and infant and child feeding practices in sub-Saharan Africa: an analysis of demographic and health surveys. Public Health Nutr. 2015; 18(17):3155-65. https://doi.org/10.1017/S1368980015002621.

39. Pratley P. Associations between quantitative measures of women's empowerment and access to care and health status for mothers and thei children: a systematic review of evidence from the developing world. Soc Sci Med. 2016;169:119-31. https://doi.org/10.1016/j.socscimed.2016.08.001.

\section{Ready to submit your research? Choose BMC and benefit from:}

- fast, convenient online submission

- thorough peer review by experienced researchers in your field

- rapid publication on acceptance

- support for research data, including large and complex data types

- gold Open Access which fosters wider collaboration and increased citations

- maximum visibility for your research: over $100 \mathrm{M}$ website views per year

At BMC, research is always in progress.

Learn more biomedcentral.com/submissions 